\title{
SRD5A3 defective congenital disorder of glycosylation: clinical utility gene card
}

\author{
Jaak Jaeken ${ }^{1} \cdot$ Dirk J. Lefeber ${ }^{2} \cdot$ Gert Matthijs $^{3}$ \\ Received: 29 December 2019 / Accepted: 28 April 2020 / Published online: 18 May 2020 \\ (c) European Society of Human Genetics 2020
}

\section{DISEASE CHARACTERISTICS}

\subsection{Name of the disease (synonyms)}

CDG-Iq; ocular coloboma with ichthyosis, brain malformations, and endocrine abnormalities; Kahrizi syndrome; mental retardation, cataract, coloboma, and kyphosis, autosomal recessive; polyprenol reductase deficiency; SRD5A3-CDG; SRD5A3 deficiency; SRD5A2L1 deficiency; steroid 5 $\alpha$ reductase 3 deficiency; steroid 5- $\alpha$-reductase 2 -like deficiency.

\subsection{OMIM\# of the disease}

$612379 / 612713$.

\subsection{Name of the analysed gene or DNA/chromosome segments}

SRD5A3.

\subsection{OMIM\# of the gene}

611715.

\subsection{Mutational spectrum}

At least 15 variants have been reported: 11 nonsense variants, 3 missense variants, and a large deletion (www.lovd.

Jaak Jaeken

jaak.jaeken@kuleuven.be

1 Department of Development and Regeneration, Centre for Metabolic Diseases, University Hospital Gasthuisberg, KU Leuven, Leuven, Belgium

2 Department of Neurology, Translational Metabolic Laboratory, Radboudumc, Nijmegen, The Netherlands

3 Department of Human Genetics, KU Leuven, Leuven, Belgium
nl/SRD5A3). The standard reference sequence indicating reported variants (ENSG00000128039) and a reference for exon numbering (ENST00000264228.9) can be found at http://www.ensembl.org.

\subsection{Analytical methods}

Sanger sequencing of the five coding exons and flanking intronic sequences of the SRD5A3 gene (NCBI reference sequence: NM_024592.4).

\subsection{Analytical validation}

Sanger sequencing identifies variants in $>99 \%$ of patients. Deep intronic variants, large deletions and duplications would not be detected using this approach.

\subsection{Estimated frequency of the disease}

(Incidence at birth ("birth prevalence") or population prevalence. If known to be variable between ethnic groups, please report):

At least 38 genetically confirmed patients (from 26 families) have been reported [1-19]. The frequency and the prevalence of the disease are not known.

\subsection{Diagnostic setting}

Yes. No.
A. (Differential) diagnosis
$\bigotimes$
B. Predictive Testing
$\bigotimes$
C. Risk assessment in Relatives
D. Prenatal
$\bigotimes$
$\bigotimes$

Comment:

The clinical presentation of steroid $5 \alpha$-reductase 3 (SRD5A3) deficiency has first been reported in 2001 [1] 
and the molecular defect in 2010 [6, 7]. SRD5A3 is located in the endoplasmic reticulum (ER) membrane and catalyzes the conversion of polyprenol to dolichol. Dolichol-specific kinase transfers a phosphate from cytidine triphosphate to dolichol, and synthesis of dolicholphosphate is the step just before the start of $\mathrm{N}$-glycosylation and O-and C-mannosylation. SRD5A3-CDG is one of the some 130 known congenital disorders of glycosylation (CDG), genetic defects in protein and lipid glycosylation. Most CDG are multisystem disorders with predominant neurological involvement.

All SRD5A3-CDG patients showed psychomotor disability, and in the majority there were various combinations of other neurological abnormalities (hypotonia, ataxia, midline brain malformation, global/cerebellar vermis hypoplasia), as well as facial dysmorphism, ophthalmological abnormalities (nystagmus, visual loss, coloboma, optic disk/nerve hypoplasia) and cutaneous symptoms (hyperpigmentation, dry skin, hypertrichosis, ichthyosis, loose skin, palmoplantar keratoderma). Symptoms reported in a minority of patients were a.o. feeding problems, cardiac malformations/hypertrophy, joint hypermobility, and hepatosplenomegaly. Symptoms that may develop over time are kyphosis, cataracts and retinitis pigmentosa. Biochemical abnormalities include increased serum transaminases, hypothyroidism, and decreased blood clotting factors antithrombin and protein C. Most patients have been reported from Afghanistan, the Czech Republic, Iran, Pakistan, Poland, Puerto Rico and Turkey. Screening for the disease is performed by serum transferrin isoelectrofocusing, showing a type 1 pattern. The diagnosis is confirmed by mutation analysis of the gene. Identification of the pathogenic variant(s) will permit heterozygote detection in the family, and prenatal diagnosis.

\section{TEST CHARACTERISTICS}

\subsection{Analytical sensitivity}

(proportion of positive tests if the genotype is present)

Close to $100 \%$ when using the serum transferrin isoelectrofocusing test.

\subsection{Analytical specificity}

(proportion of negative tests if the genotype is not present)

Close to $100 \%$ when using the serum transferrin isoelectrofocusing test. This test can be positive in secondary glycosylation disturbances e.g. due to chronic alcoholism or bacterial sialidase.

\subsection{Clinical sensitivity}

(proportion of positive tests if the disease is present)

The clinical sensitivity can be dependent on variable factors such as age or family history. In such cases a general statement should be given, even if a quantification can only be made case by case.

Close to $100 \%$.

\subsection{Clinical specificity}

(proportion of negative tests if the disease is not present)

The clinical specificity can be dependent on variable factors such as age or family history. In such cases a general statement should be given, even if a quantification can only be made case by case.

Close to $100 \%$.

\subsection{Positive clinical predictive value}

(life time risk to develop the disease if the test is positive) $100 \%$, based on positive serum transferrin isoelectrofocusing screening and SRD $5 A 3$ mutation analysis.

\subsection{Negative clinical predictive value}

\section{(Probability not to develop the disease if the test is} negative)

Assume an increased risk based on family history for a non-affected person. Allelic and locus heterogeneity may need to be considered.

Index case in that family had been tested:

$100 \%$

Index case in that family had not been tested:

$100 \%$ 


\section{CLINICAL UTILITY}

\section{1 (Differential) diagnostics: The tested person is clinically affected}

(To be answered if in 1.9 "A" was marked)

3.1.1 Can a diagnosis be made other than through a genetic test?

No.

$\bigotimes$ (continue with 3.1.4)

Yes,

$$
\begin{aligned}
& \text { Clinically } \\
& \text { Imaging } \\
& \text { Endoscopy } \\
& \text { Biochemistry } \\
& \text { Electrophysiology } \\
& \text { Other (please describe) }
\end{aligned}
$$

3.1.2 Describe the burden of alternative diagnostic methods to the patient

Not applicable.

3.1.3 How is the cost effectiveness of alternative diagnostic methods to be judged?

Not applicable.

3.1.4 Will disease management be influenced by the result of a genetic test?

No.

Yes. $\triangle$

Therapy (please Treatment of SRD5A3-CDG is describe) purely symptomatic.

Prognosis (please The prognosis regarding quality of describe) life is mainly determined by the nature and the degree of the brain and eye involvement.

Management Since SRD5A3-CDG is a multi(please describe) system disease, follow-up by a multidisciplinary team is mandatory.
3.2 Predictive Setting: The tested person is clinically unaffected but carries an increased risk based on family history

(To be answered if in 1.9 "B" was marked).

3.2.1 Will the result of a genetic test influence lifestyle and prevention?

If the test result is positive (please describe):

Not applicable.

If the test result is negative (please describe): Not applicable.

3.2.2 Which options in view of lifestyle and prevention does a person at-risk have if no genetic test has been done (please describe)?

Not applicable.

\subsection{Genetic risk assessment in family members of a diseased person}

(To be answered if in 1.9 "C" was marked).

3.3.1 Does the result of a genetic test resolve the genetic situation in that family?

Usually yes, by testing the potential heterozygous persons (carriers) in the family.

3.3.2 Can a genetic test in the index patient save genetic or other tests in family members?

No.

3.3.3 Does a positive genetic test result in the index patient enable a predictive test in a family member?

Not applicable.

\subsection{Prenatal diagnosis}

(To be answered if in 1.9 "D" was marked).

3.4.1 Does a positive genetic test result in the index patient enable a prenatal diagnosis?

Yes. Prenatal diagnosis should be performed by molecular analysis. 


\section{IF APPLICABLE, FURTHER CONSEQUENCES OF TESTING}

Please assume that the result of a genetic test has no immediate medical consequences. Is there any evidence that a genetic test is nevertheless useful for the patient or his/her relatives? (Please describe).

Knowledge of the diagnosis will stop unnecessary further investigations. It will also help patients and parents of affected children in the process of accepting the disease although no curative treatment is yet available.

Acknowledgements This work was supported by EuroGentest2 (Unit 2: "Genetic testing as part of health care"), a Coordination Action under FP7 (Grant Agreement Number 261469) and the European Society of Human Genetics.

\section{Compliance with ethical standards}

Conflict of interest The authors declare that they have no conflict of interest.

Publisher's note Springer Nature remains neutral with regard to jurisdictional claims in published maps and institutional affiliations.

\section{References}

1. Assmann B, Hackler R, Peters V, et al. A new subtype of a congenital disorder of glycosylation (CDG) with mild clinical manifestations. Neuropediatrics. 2001;32:313-8.

2. Prietsch V, Peters V, Hackler R, et al. A new case of CDG-x with stereotyped dystonic hand movements and optic atrophy. J Inherit Metab Dis. 2002;25:126-30.

3. Al-Gazali L, Hertecant J, Algawi K, El Teraifi H, Dattani M, et al. A new autosomal recessive syndrome of ocular colobomas, ichthyosis, brain malformations and endocrine abnormalities in an inbred Emirati family. Am J Med Genet A. 2008;146A:813-9.

4. Kahrizi K, Najmabadi H, Kariminejad R, et al. An autosomal recessive syndrome. Eur J Hum Genet. 2009;1:125-8.

5. Morava E, Wosik HN, Sykut-Cegielska J, et al. Ophthalmological abnormalities in children with congenital disorders of glycosylation type I. Br J Ophthalmol. 2009;93:350-4.
6. Cantagrel V, Lefeber DJ, Ng BG, et al. SRD5A3 is required for converting polyprenol to dolichol and is mutated in a congenital glycosylation disorder. Cell. 2010;142:203-17.

7. Morava E, Wevers RA, Cantagrel V, et al. A novel cerebelloocular syndrome with abnormal glycosylation due to abnormalities in dolichol metabolism. Brain. 2010;133:3210-20.

8. Kahrizi K, Hu CH, Garshasbi M, et al. Next generation sequencing in a family with autosomal recessive Kahrizi syndrome (OMIM 612713) reveals a homozygous frameshift mutation in SRD5A3. Eur J Hum Genet. 2011;19:115-7.

9. Gründahl JE, Guan Z, Rust S, et al. Life with too much polyprenol: polyprenol reductase deficiency. Mol Genet Metab. 2012;105:642-51.

10. Kasapkara CS, Tümer L, Ezgü FS, et al. SRD5A3-CDG: a patient with a novel mutation. Eur J Paediatr Neurol. 2012;16:554-6.

11. Al-Sarraj Y, Ben-Omran T, Tolefat M, Bejaoui Y, El-Shanti H, Kambouris M. A novel missense mutation in SRD5A3 causes congenital disorder of glycosylation type I (Cerebello-OcularSyndrome). J Inborn Errors Metab Screen. 2014;2:3-7.

12. Kara B, Ayhan Ö, Gökçay G, Başboğaoğlu N, Tolun A. Adult phenotype and further phenotypic variability in SRD5A3-CDG. BMC Med Genet. 2014;15:10.

13. Tuysuz B, Pehlivan D, Özkök A, et al. Phenotypic expansion of congenital disorder of glycosylation due to SRD5A3 null mutation. JIMD Rep. 2016;26:7-12.

14. Wheeler PG, Ng BG, Sanford L, et al. SRD5A3-CDG: expanding the phenotype of a congenital disorder of glycosylation with emphasis on adult onset features. Am J Med Genet A. 2016;170A:3165-71.

15. Taylor RL, Arno G, Poulter JA, et al. Association of steroid $5 \alpha$-reductase type 3 congenital disorder of glycosylation with early-onset retinal dystrophy. JAMA Ophthalmol. 2017;135: 339-47.

16. Gupta N, Verma G, Kabra M, Bijarnia-Mahay S, Ganapathy A. Identification of a case of SRD5A3-congenital disorder of glycosylation (CDG1Q) by exome sequencing. Indian J Med Res. 2018;147:422-6.

17. Khan AO. Early-onset retinal dystrophy and chronic dermatitis in a girl with an undiagnosed congenital disorder of glycosylation (SRD5A3-CDG). Ophthalmic Genet. 2018;39:628-30.

18. Kousal B, Honzík T, Hansíková $\mathrm{H}$, et al. Review of SRD5A3 disease-causing sequence variants and ocular findings in steroid $5 \alpha$-reductase type 3 congenital disorder of glycosylation, and a detailed new case. Folia Biologica (Praha). 2019;65:134-41.

19. Medrano C, Vega A, Navarrete R, et al. Clinical and molecular diagnosis of non-phosphomannomutase $2 \mathrm{~N}$-linked congenital disorders of glycosylation in Spain. Clin Genet. 2019;95:615-26. 